\title{
Estimating probability of germline mismatch repair mutations in colorectal cancer patients with microsatellite stable tumors
}

\author{
Jessica N Everett ${ }^{1 *}$, Victoria M Raymond ${ }^{1}$, Michele Gornick², Rajesh S Mangrulkar ${ }^{1}$, Ignacio Blanco ${ }^{3}$, \\ Stephen B Gruber ${ }^{4}$
}

From 14th Annual Meeting of the Collaborative Group of the Americas on Inherited Colorectal Cancer Dallas, TX, USA. 12-13 October 2010

\section{Background}

Microsatellite instability (MSI) is a hallmark of DNA mismatch repair (MMR) deficiency and is an established screening tool for identifying Lynch syndrome in colorectal cancer populations [1]. However, MSI testing is neither perfectly sensitive nor specific to detect Lynch Syndrome, and germline MMR mutations have been reported in patients with microsatellite stable (MSS) tumors [2]. The value of germline MMR testing in patients with MSS tumors may vary based on family history, and data is needed to guide choices about when to offer testing in high risk clinic settings.

\section{Materials and methods}

From 2002-2009, high risk patients presenting to the Cancer Genetics Clinics at the University of Michigan and the Catalan Institute of Oncology in Barcelona, Spain were evaluated for Lynch syndrome and included in the present study. Patients with MSS colorectal tumors who also had germline MMR testing were eligible for analysis. We calculated risk for MMR mutation using MMRPro v.5.1 [3] at baseline, after MSI testing, and after germline MMR testing. Modified likelihood ratios were estimated to evaluate the utility of germline testing in patients with MSS tumors based on the strength of the family history [4].

\section{Results}

Germline MMR mutations were identified in 5/44 (11.4\%) patients with MSS tumors. Two of the mutations were

\footnotetext{
* Correspondence: jever@umich.edu

'Department of Internal Medicine, University of Michigan, Ann Arbor,

Michigan, 48109, USA

Full list of author information is available at the end of the article
}

identified in patients from families that met the Amsterdam Criteria (AC I/II), whereas 3 mutations were found in patients from families that were AC I/II negative. The modified likelihood for a germline mutation $\left(+\mathrm{LR}_{\mathrm{mod}}\right)$ in an AC I/II patient was 1.56 (95\% CI: 0.47 - 5.18) and the modified negative likelihood ratio $\left(-\mathrm{LR}_{\bmod }\right)$ for a patient not meeting the AC I/II criteria was 0.81 (95\% CI: 0.39 1.69). We quantified the meaning of the AC I/II criteria to guide clinical choices about genetic testing in MSS tumors by multiplying the pretest odds by the $+\mathrm{LR}_{\text {mod }}$ and the $-L R_{\text {mod }}$. The probability of a mutation was modified from a baseline of $11.4 \%$ to $16.7 \%$ in $\mathrm{AC}$ I/II families, compared to $9.4 \%$ in AC I/II-negative families.

\section{Conclusions}

Germline MMR testing in high risk patients with MSS colorectal tumors identifies mutations in a small, but meaningful proportion of patients. The diagnostic yield is dependent on the strength of the family history. Modified likelihood ratios can be helpful to quantify the probability of a positive gene test for Lynch Syndrome, and can be applied to pre-test probabilities derived from clinical models.

\footnotetext{
Author details

${ }^{1}$ Department of Internal Medicine, University of Michigan, Ann Arbor, Michigan, 48109, USA. ${ }^{2}$ Department of Human Genetics, University of Michigan, Ann Arbor, Michigan, 48109, USA. ${ }^{3}$ Cancer Genetic Counseling Program, IDIBELL-Institut Català d'Oncologia, Barcelona, 08907, Spain. ${ }^{4}$ Department of Internal Medicine, Epidemiology, and Human Genetics, University of Michigan, Ann Arbor, Michigan, 48109, USA.
}

Published: 10 March 2011 


\section{References}

1. Hampel H, Frankel WL, Martin E, Arnold M, Khanduja K, Kuebler P.

Nakagawa H, Sotamaa K, Prior TW, Westman J, Panescu J, Fix D, Lockman J, Comeras I, de la Chapelle A: Screening for Lynch Syndrome (Hereditary Nonpolyposis Colorectal Cancer). N Engl J Med 2005, 352:1851-1860.

2. Lagerstedt Robinson $K$, Liu T, Vandrovcova J, Halvarsson B, Clendenning M, Frebourg T, Papadopoulos N, Kinzler KW, Vogelstein B, Peltomaki P, Kolodner RD, Nilbert M, Lindblom A: Lynch Syndrome (Hereditary Nonpolyposis Colorectal Cancer) diagnostics. JNCI 2007, 99:291-299.

3. Chen S, Wang W, Lee S, Nafa K, Lee J, Romans K, Watson P, Gruber SB, Euhus D, Kinzler KW, Jass J, Gallinger S, Lindor NM, Casey G, Ellis N, Giardiello FM, Offit K, Parmigiani G: Prediction of germline mutations and cancer risk in the Lynch Syndrome. JAMA 2006, 296:1479-1487.

4. Simel DL, Samsa GP, Matchar DB: Likelihood ratios with confidence: sample size estimation for diagnostic test studies. J Clin Epidemiol 1991, 44:763-770.

doi:10.1186/1897-4287-9-S1-P12

Cite this article as: Everett et al.: Estimating probability of germline mismatch repair mutations in colorectal cancer patients with microsatellite stable tumors. Hereditary Cancer in Clinical Practice 2011 9(Suppl 1):P12.

\section{Submit your next manuscript to BioMed Central} and take full advantage of:

- Convenient online submission

- Thorough peer review

- No space constraints or color figure charges

- Immediate publication on acceptance

- Inclusion in PubMed, CAS, Scopus and Google Scholar

- Research which is freely available for redistribution

Submit your manuscript at www.biomedcentral.com/submit 